\title{
ACTH adenomas transforming their clinical expression: report of 5 cases
}

\author{
Matteo Zoli, MD, ${ }^{1}$ Marco Faustini-Fustini, MD, ${ }^{2}$ Diego Mazzatenta, MD, ${ }^{1}$ \\ Gianluca Marucci, MD, PhD, ${ }^{3}$ Eugenio De Carlo, MD, ${ }^{4}$ Antonella Bacci, MD, ${ }^{5}$ \\ Ernesto Pasquini, MD, ${ }^{6}$ Giuseppe Lanzino, MD, ${ }^{7}$ and Giorgio Frank, MD'
}

${ }^{1}$ Center of Surgery for Pituitary Tumors and Endoscopic Skull Base Surgery, and ${ }^{2}$ RCCS Istituto delle Scienze Neurologiche di Bologna; ' ${ }^{3}$ epartment of Biomedical and NeuroMotor Sciences (DiBiNeM), Section of Pathology "M. Malpighi," Bellaria Hospital, University of Bologna, Bologna; ' ${ }^{4}$ Department of Medical and Surgical Sciences, Padova University, Padova; ${ }^{5}$ Department of Neuroradiology, IRCCS Istituto delle Scienze Neurologiche di Bologna; ${ }^{6}$ ENT Department, Azienda USL, Bologna, Italy; and ${ }^{7}$ Department of Neurologic Surgery, Mayo Clinic, Rochester, Minnesota

\begin{abstract}
OBJECT Adrenocorticotropic hormone (ACTH) adenomas have been recognized as a more aggressive and invasive subtype of pituitary adenomas. An additional and clinically relevant peculiarity of these tumors is their ability to modify their clinical expression from a silent form to Cushing disease or vice versa. The aim of this study was to review a series of patients with pituitary adenomas and analyze the clinical implications of the transformation of clinical expression in 5 cases that showed this phenomenon .

METHODS The authors retrospectively reviewed a series of patients with pituitary adenoma and collected clinical, biohumoral, and neuroradiological data of those who presented with a transformation from silent ACTH adenomas to functioning tumors or vice versa. In all the cases, preoperative assessment consisted of brain MRI, ophthalmological examination, and complete baseline endocrinological investigation. In patients with clinical and/or biochemical findings suspicious for Cushing syndrome, a low-dose dexamethasone suppression test was performed to rule in or out this diagnosis. Endocrinological evaluations were repeated 1 month after surgery, 3 months after surgery, and every 6 months or annually thereafter. Ophthalmological evaluations and brain MRIs were repeated after 3 months and then every 6 or 12 months thereafter.
\end{abstract}

RESULTS Five patients ( 2 men and 3 women) included in this series had corticotropic tumors that showed transformation from an endocrinologically silent form to manifest Cushing disease and vice versa. The mean age at presentation was 40 years (range 18-51 years). In 3 of these patients, a transformation from silent to functioning ACTH adenoma with manifest Cushing disease occurred. In 1 patient, the authors observed the transition from a functioning to a silent adenoma with spontaneous resolution of hypercortisolism. Another patient's silent adenoma "shifted" to a functioning adenoma and then regressed back to a silent form with spontaneous resolution of Cushing disease. This patient again developed hypercortisolism, which finally resolved spontaneously. In this series, the transformation occurred after a mean of 3.5 years (range 6 months to 7 years). The shift from an ACTH-silent to a functioning adenoma was observed in $9 \%$ of the ACTH-silent adenomas in this series (4 of 44 cases), and the spontaneous remission of Cushing disease to a silent corticotroph cell adenoma occurred in $1.5 \%$ of cases of this series ( 2 of 132 functioning ACTH adenomas). At follow-up (mean 107 months; range 60-177 months), cortisol levels were within normal limits in all 5 cases. However, 1 patient required Gamma Knife radiosurgery and eventually adrenalectomy for disease control to be achieved.

CONCLUSIONS The ability of silent ACTH adenomas to transform their secretion pattern poses a challenge for neurosurgeons and endocrinologists. Because the transformation is often unexpected, the clinical and biochemical data can be underestimated. Furthermore, this bizarre and unpredictable postoperative tumor behavior can lead to misinterpretation of clinical and endocrinological outcomes. Even if these cases are very rare, they are not anecdotal in large series. Thus, ACTH adenomas require careful biohumoral and neuroradiological follow-up to detect possible transformations. http://thejns.org/doi/abs/10.3171/2014.11.FOCUS14679

KEY WORDS endoscopic endonasal surgery; silent ACTH pituitary adenoma; Cushing disease; radiosurgery; hypercortisolism

ABBREVIATIONS ACTH = adrenocorticotropic hormone; FSH = follicle-stimulating hormone; LDDST = low-dose dexamethasone suppression test; LH = luteinizing hormone; $\mathrm{LI}=$ label index SUBMITTED September 30, 2014. ACCEPTED November 4, 2014.

INCLUDE WHEN CITING DOI: 10.3171/2014.11.FOCUS14679.

DISCLOSURE The authors report no conflict of interest concerning the materials or methods used in this study or the findings specified in this paper. 
$\mathrm{S}$ INCE the discovery of silent corticotropic adenomas by Kovacs et al..$^{12}$ in 1978 , this subtype has been recognized as more aggressive and invasive than other pituitary adenomas. ${ }^{5,9,10,14,19} \mathrm{~A}$ lesser-known peculiarity of tumors of this subtype is their ability to modify their clinical expression from an endocrinologically silent form to manifest Cushing disease and vice versa. This peculiar and unique clinical behavior of originally silent corticotropic adenomas has been reported sporadically. ${ }^{1,3,6,13,15-17,20}$ In this study, we reviewed a series of patients with pituitary adenomas and studied 5 cases of corticotropic tumors that presented this "shift" from silent adrenocorticotropic hormone $(\mathrm{ACTH})$ adenomas to functioning tumors or vice versa; our aim was to analyze this phenomenon, which can have relevant clinical implications in the management of these patients.

\section{Methods}

We retrospectively reviewed the records of 1259 consecutive endoscopic endonasal procedures for pituitary adenomas from May 1998 to December 2013 at the IRCCS Istituto delle Scienze Neurologiche di Bologna. Of these tumors, 132 were histologically proven ACTHsecreting adenomas associated with Cushing disease and 44 were originally silent corticotropic adenomas. We then analyzed data obtained in those cases that presented a clinical and biochemical shift from ACTH-silent to active ACTH-secreting tumors or vice versa. Routine preoperative assessments included brain MRI, ophthalmological examination (acuity and visual field assessment), and complete baseline endocrinological investigations (to obtain serum levels of prolactin, thyroid-stimulating hormone, free thyroxine, luteinizing hormone [LH], folliclestimulating hormone [FSH], growth hormone, insulin-like growth factor I, ACTH, cortisol, and 24-hour urinary free cortisol). Information about clinical and biochemical signs of diabetes insipidus was also collected. For patients with clinical and/or biochemical findings suspicious for Cushing syndrome, a low-dose dexamethasone suppression test (LDDST) was performed to rule in or out this diagnosis.

Surgery was performed through an endoscopic endonasal approach in all but 1 patient, in whom there was an asymmetrical suprasellar extension of the tumor that was treated through a craniotomy. In patients with a subfrontal expansion of the tumor or a major or exclusive suprasellar component, the endoscopic endonasal approach was extended to the planum/tuberculum sellae. Immediately after surgery, corticosteroid replacement therapy was started to treat silent corticotropic macroadenomas. In the case of ACTH-secreting adenomas with manifest Cushing disease, careful monitoring of serial serum cortisol levels without prophylactic corticosteroid replacement therapy was preferred. When cortisol levels fell to less than $50 \mathrm{ng} /$ $\mathrm{ml}$, or in cases of adrenal crisis, hydrocortisone replacement therapy was begun.

Histopathological analyses were performed on specimens fixed in $10 \%$ buffered formalin and embedded in paraffin. Paraffin sections of $4 \mu \mathrm{m}$ were serially cut and underwent $\mathrm{H} \& \mathrm{E}, \mathrm{PAS}$, and reticulin staining. Serial 4- $\mu \mathrm{m}-$ thick paraffin sections mounted on precoated slides were processed using standardized automated procedures with prediluted antibodies (Ventana-Benchmark). Immunohistochemistry was performed using Polymer as the detection system (UltraVision LP Detection System HRP Polymer; Lab Vision). The prediluted antibodies were anti-growth hormone (polyclonal), anti-ACTH (polyclonal), anti-prolactin (polyclonal), anti-thyroid-stimulating hormone (polyclonal), anti-FSH (polyclonal), anti-LH (polyclonal), and cytokeratin Cam 5.2 (clone 5D3). Appropriate positive and negative controls were used. The Ki-67 (clone 30-9, prediluted; Ventana) label index [LI] was calculated as the percentage of positive cells per high power field (hpf) $(\times 400$, Neofluar $0.25 \mathrm{~mm}^{2}$; Zeiss). We manually measured $10 \mathrm{hpf}$ in each case.

The postoperative assessment included an endocrinological evaluation 30 days after surgery and then at 3,6, and 12 months. Conversely, the ophthalmological assessment and MRI were performed 3 and 6 or 12 months after surgery. After the 1st year, clinical, biochemical, and neuroradiological follow-up evaluations were repeated every 6-12 months. We also collected data regarding complications, sequelae, and additional treatments after surgery, including medical therapy, radiotherapy, or adrenalectomy.

\section{Results}

Five patients ( 2 men and 3 women) included in this series had corticotropic tumors that presented transformation of clinical expression from silent ACTH adenomas to functioning tumors or vice versa (Table 1). The mean age at presentation was 40 years (18-51 years). In 3 cases, a transformation from silent to functioning ACTH adenoma with manifest Cushing disease occurred. In 1 patient we observed the transition from a functioning to a silent adenoma with spontaneous recovery of hypercortisolism. An additional patient shifted from having a silent to a functioning adenoma followed by regression back to a silent form with spontaneous resolution of Cushing disease. She then again developed hypercortisolism, which finally resolved spontaneously. The biochemical data of these patients are reported in Table 2.

In our series, the transformation occurred after a mean of 3.5 years (6 months to 7 years). All the cases involved macroadenomas; 3 presented with cavernous sinus invasion, and 3 had cystic components at the time of initial diagnosis.

The shift from ACTH-silent to functioning adenoma

TABLE 1. Clinical features of patients in the series

\begin{tabular}{cclc}
\hline $\begin{array}{c}\text { Case } \\
\text { No. }\end{array}$ & $\begin{array}{c}\text { Age (yrs), } \\
\text { Sex }\end{array}$ & \multicolumn{1}{c}{ Transformation } & $\begin{array}{c}\text { Time to } \\
\text { Transformation(s) (yrs) }\end{array}$ \\
\hline 1 & $47, \mathrm{~F}$ & Silent to functioning & 7 \\
\hline 2 & $51, \mathrm{M}$ & Functioning to silent & 1 \\
\hline 3 & $18, \mathrm{~F}$ & Silent to functioning & 6 \\
\hline 4 & $37, \mathrm{~F}$ & $\begin{array}{l}\text { Silent to functioning to } \\
\text { silent to functioning to } \\
\text { silent }\end{array}$ & 2 (mean) \\
\hline 5 & $48, \mathrm{M}$ & Silent to functioning & 2 \\
\hline
\end{tabular}


TABLE 2. Variations in serum ACTH, serum cortisol, and urinary free-cortisol levels in the 5 cases of the series

\begin{tabular}{|c|c|c|c|c|c|c|c|c|}
\hline Case 1 & Jan 2000 & Nov 2003 & Jun 2005 & Jan 2007 & Mar 2007 & Jun 2008 & Jun 2010 & Sep 2014 \\
\hline Serum ACTH $(\mathrm{pg} / \mathrm{ml})^{*}$ & 81.7 & 88 & 88 & 61 & 31 & 60 & 43 & 1008 \\
\hline Serum cortisol (ng/ml)† & 240 & 221 & 220 & 253 & 265 & 341 & 324 & $\ddagger$ \\
\hline Urinary free cortisol $(\mu \mathrm{g} / 24 \mathrm{hrs}) \S$ & 116 & 77 & 88 & 240 & 102 & 116 & 170 & $\ddagger$ \\
\hline Case 2 & Apr 2003 & Jul 2003 & Jan 2004 & Jun 2004 & Mar 2006 & Sep 2014 & & \\
\hline Serum ACTH (pg/ml) & 130 & 72.5 & 48.6 & 59.8 & 30.3 & 26 & & \\
\hline Serum cortisol (ng/ml) & 310 & 180 & 71.7 & 10 & ף & ף & & \\
\hline Urinary free cortisol ( $\mu \mathrm{g} / 24 \mathrm{hrs})$ & 146 & 83 & 35 & 9.7 & 32 & 48 & & \\
\hline Case 3 & Nov 2006 & Sep 2012 & Dec 2012 & Sep 2014 & & & & \\
\hline Serum ACTH (pg/ml) & 40 & 21.51 & 9 & 16 & & & & \\
\hline Serum cortisol (ng/ml) & 220 & 412 & П & ף & & & & \\
\hline Urinary free cortisol ( $\mu \mathrm{g} / 24 \mathrm{hrs})$ & - & 210 & 35 & 28 & & & & \\
\hline Case 4 & Sep 2006 & Mar 2007 & Aug 2012 & Jan 2013 & May 2014 & & & \\
\hline Serum ACTH (pg/ml) & 1500 & 150 & 608 & 107 & 143 & & & \\
\hline Serum cortisol (ng/ml) & 107.4 & 6.4 & 445 & 164 & ף & & & \\
\hline Urinary free cortisol ( $\mu \mathrm{g} / 24 \mathrm{hrs})$ & 630 & 46 & 540 & - & - & & & \\
\hline Case 5 & Apr 2007 & May 2009 & Feb 2010 & Sep 2014 & & & & \\
\hline Serum ACTH (pg/ml) & 48.8 & 127.9 & 14.4 & 21.5 & & & & \\
\hline Serum cortisol (ng/ml) & 133 & 306 & П & ף & & & & \\
\hline Urinary free cortisol ( $\mu \mathrm{g} / 24 \mathrm{hrs})$ & 299.6 & 1307.5 & 391 & 396 & & & & \\
\hline \multicolumn{9}{|c|}{ 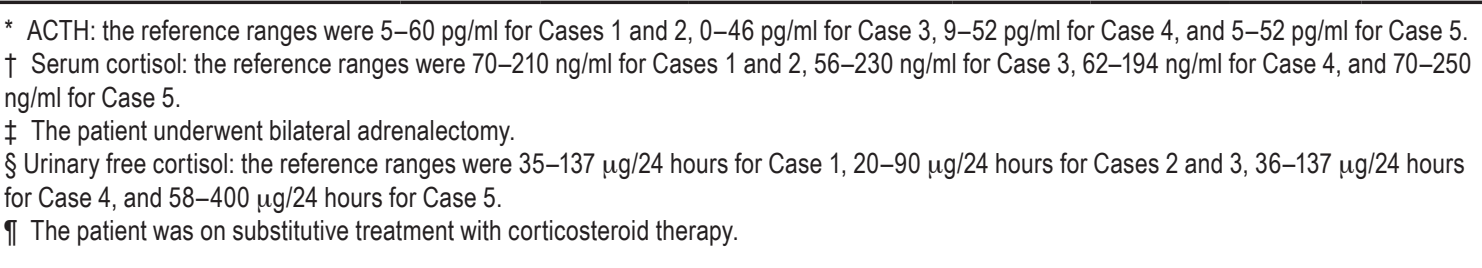 } \\
\hline
\end{tabular}

in this series was observed in $9 \%$ of the cases of ACTHsilent adenoma (4 of 44 cases), and spontaneous remission of Cushing disease to a silent corticotroph cell adenoma occurred in $1.5 \%$ of the cases ( 2 of 132 functioning ACTH adenomas).

Histopathological analysis of specimens obtained during the first surgery revealed a densely granulated corticotroph adenoma in 1 case (Case 2), Type I silent corticotroph adenomas in 2 cases (Cases 1 and 3 ), and Type II silent corticotroph adenomas in 2 cases (Cases 4 and 5). Pathological features are reported in Table 3.

In the case of the densely granulated corticotroph ad- enoma, the tumors removed in the first and the following surgeries shared similar morphological (basophilic neoplastic cell) and architectural (trabecular) features (Fig. 1a). PAS stained the first tumor moderately but stained the recurring tumors only faintly. Neoplastic cells were intensely immunopositive for ACTH and cytokeratin Cam 5.2, and the $\mathrm{Ki}-67 \mathrm{LI}$ was around $2 \%$. At recurrence, the surgical specimen contained islands of nonneoplastic corticotrophs, which did not show any Crooke hyaline changes.

In the 2 cases of Type I silent corticotroph adenoma, microscopic examination revealed cellular tumors composed of neoplastic cells with basophilic cytoplasm arranged in

TABLE 3. Pathological findings

\begin{tabular}{|c|c|c|}
\hline \multirow{2}{*}{$\begin{array}{l}\text { Case } \\
\text { No. }\end{array}$} & \multicolumn{2}{|c|}{ Laboratory Data } \\
\hline & From Op Before Transformation & From Op After Transformation \\
\hline 1 & $\begin{array}{l}\text { Chromophobic cytoplasm, PAS negative, diffuse pat- } \\
\text { tern, } \mathrm{ACTH}=10 \%, \mathrm{Ki}-67 \mathrm{LI}=2 \%\end{array}$ & PAS negative, trabecular pattern, ACTH $=80 \%, \mathrm{Ki}-67 \mathrm{LI}=2 \%$ \\
\hline 2 & $\begin{array}{l}\text { Basophilic cytoplasm, PAS faint, trabecular pattern, } \\
\qquad \text { ACTH }=90 \%, \mathrm{Ki}-67 \mathrm{LI}=2 \%\end{array}$ & $\begin{array}{l}\text { Basophilic cytoplasm, PAS faint, trabecular pattern, ACTH = } \\
80 \%, \mathrm{Ki}-67 \mathrm{LI}=1.5 \%\end{array}$ \\
\hline 3 & $\begin{array}{l}\text { Chromophobic cytoplasm, PAS negative, solid pattern, } \\
\qquad \text { ACTH }=20 \%, \mathrm{Ki}-67 \mathrm{LI}=1 \%\end{array}$ & $\begin{array}{l}\text { Chromophobic cytoplasm, PAS negative, solid pattern, } \mathrm{ACTH}= \\
\quad 70 \%, \mathrm{Ki}-67 \mathrm{LI}=2 \%\end{array}$ \\
\hline 4 & $\begin{array}{l}\text { Basophilic cytoplasm, PAS weak, solid \& trabecular } \\
\text { pattern, } \mathrm{ACTH}=90 \%, \mathrm{Ki}-67 \mathrm{LI}=2 \%\end{array}$ & $\begin{array}{l}\text { Basophilic cytoplasm, PAS weak, solid \& trabecular pattern, } \\
\qquad \mathrm{ACTH}=75 \%, \mathrm{Ki}-67 \mathrm{LI}=2.5 \%\end{array}$ \\
\hline 5 & No surgery & $\begin{array}{l}\text { Basophilic cytoplasm, PAS moderate, solid pattern, ACTH = } \\
80 \%, \mathrm{Ki}-67 \mathrm{LI}=2 \%\end{array}$ \\
\hline
\end{tabular}




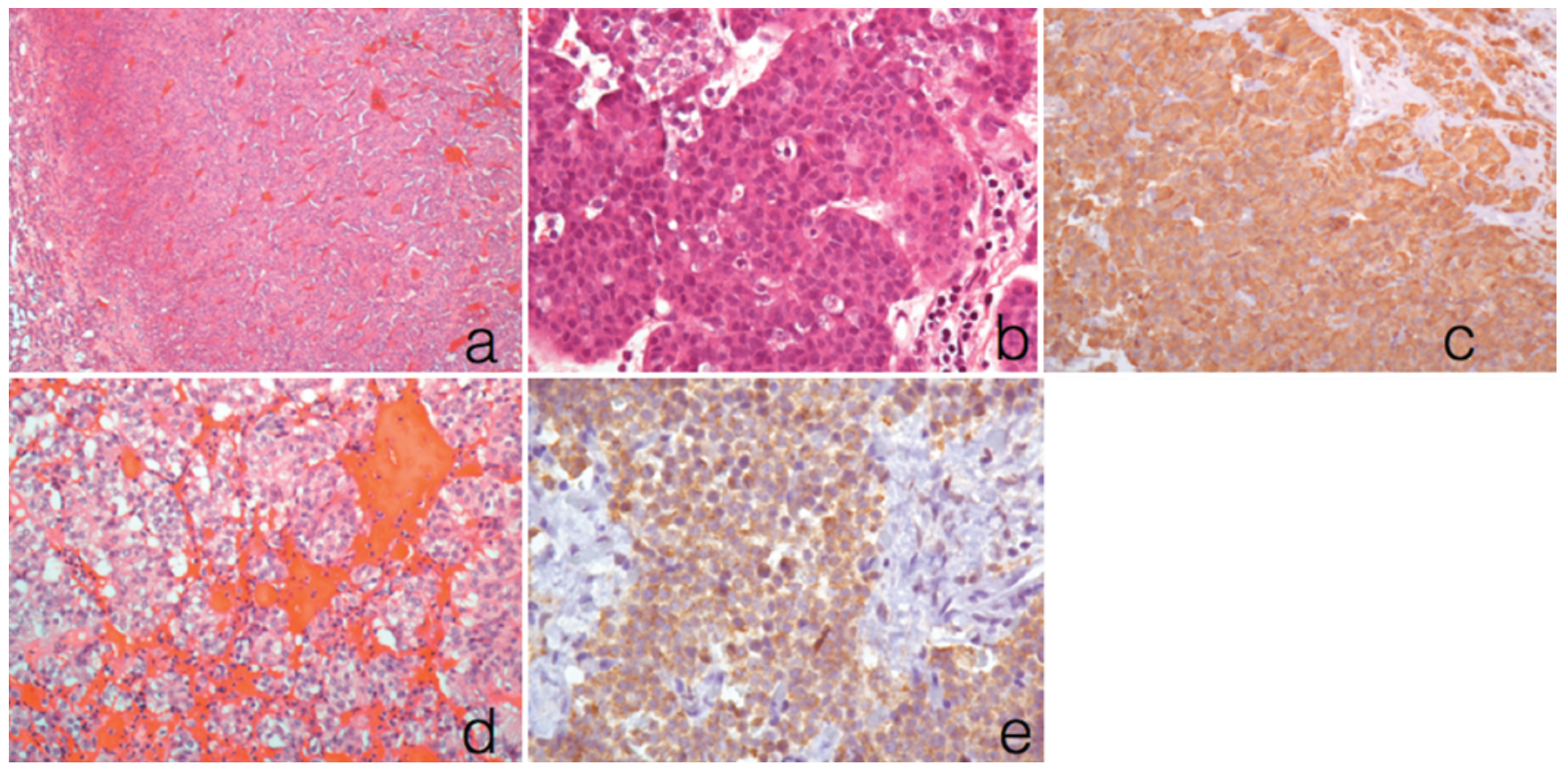

FIG. 1. Photomicrographs. a: Case 2. The tumor is composed of neoplastic cells with basophilic cytoplasm arranged in a trabecular pattern. On the left side, islands of nonneoplastic corticotrophs can be seen. $\mathrm{H} \& \mathrm{E}$, original magnification $\times 40$. b: Case 1. The tumor showed a solid pattern of growth. No mitotic activity or significant atypia was present. $\mathrm{H} \& \mathrm{E}$, original magnification $\times 200$. c: Case 4. Neoplastic cells displayed strong immunopositivity for ACTH. Anti-ACTH antiserum, original magnification $\times 100$. d: Case 3. On histological examination, diffuse proliferation of neoplastic cells with chromophobic cytoplasm can be seen. $H$ \& $E$, original magnification $\times 200$. e: Case 5 . In this case, immunoreactivity for ACTH was weak but not difficult to identify. AntiACTH antiserum, original magnification $\times 200$.

a trabecular or solid pattern (Fig. 1b). The tumors stained weakly with PAS and had strong immunopositivity for ACTH (between $70 \%$ and $90 \%$ neoplastic cells) (Fig. 1c) and for cytokeratin Cam 5.2. The Ki-67 LI was less than $3 \%$ in all cases. The tumors obtained during subsequent surgeries retained morphological and immunohistochemical findings similar to those observed in tumors removed during the first surgery.

In the cases of Type II silent corticotroph adenoma, tumors from the first surgery presented diffuse proliferation of neoplastic cells with chromophobic cytoplasm (Fig. 1d). These cells were negative with PAS staining and exhibited less immunoreactivity for ACTH (Fig. 1e) than the cells from the other cases, while cytokeratin immunoreactivity was intense. The tumors from subsequent surgeries maintained morphological, PAS-staining, and cytokeratin findings similar to those observed in the tumors obtained from the first surgery, and immunoreactivity for ACTH was increased significantly. In these cases, the Ki-67 LI was about $2 \%$ in analyzed specimens from the first and subsequent surgeries.

At follow-up (mean 107 months; range 60-177 months), cortisol levels were within normal limits in all 5 cases. However, 1 patient required Gamma Knife radiosurgery and eventually adrenalectomy to achieve disease control.

\section{Case Reports Case 1}

A 47-year-old woman presented in January 2000 with an incidental finding of a cystic adenoma with suprasellar extension found with MRI performed after a spontaneous facial nerve palsy (Fig. 2a). The tumor was causing incomplete bitemporal hemianopsia. She had a history of treated hypertension and thyroidectomy and required hormone replacement therapy. She did not have any symptoms or signs of Cushing disease. Biochemical assays revealed normal pituitary function. Her serum cortisol and ACTH levels were slightly elevated $(240 \mathrm{ng} / \mathrm{ml}$ [reference range $70-210 \mathrm{ng} / \mathrm{ml}$ ] and $81.7 \mathrm{pg} / \mathrm{ml}$ [reference range 5-60 pg/ $\mathrm{ml}]$, respectively), and her urinary free cortisol level was within the normal range (116 $\mu \mathrm{g} / 24$ hours [reference range 35-137 $\mu \mathrm{g} / 24$ hours]). An LDDST (Liddle I test) was then performed; her serum cortisol level fell below $18 \mathrm{ng} / \mathrm{ml}$, which led us to exclude real hypercortisolemia and to consider mild cortisol elevation, possibly consistent with a stress reaction to hospitalization and corticosteroid therapy for her facial nerve palsy. She underwent transsphenoidal surgery, and radical tumor resection was achieved. On histopathological examination, immunostaining of the tumor revealed a Type I corticotroph adenoma, and $10 \%$ of the cells were positive for ACTH (Table 2). Her postoperative course was uneventful, her pituitary function remained normal postoperatively, and her visual field deficits had resolved by the 3-month evaluation. Follow-up MRI confirmed radical tumor resection (Fig. 2b).

Three years later, a small asymptomatic recurrence with left cavernous sinus invasion was noted on routine followup MRI (Fig. 2c). Results of an endocrinological evaluation again were unremarkable, with slight ACTH hypersecretion $(88 \mathrm{pg} / \mathrm{ml})$ without hypercortisolism (serum corti- 

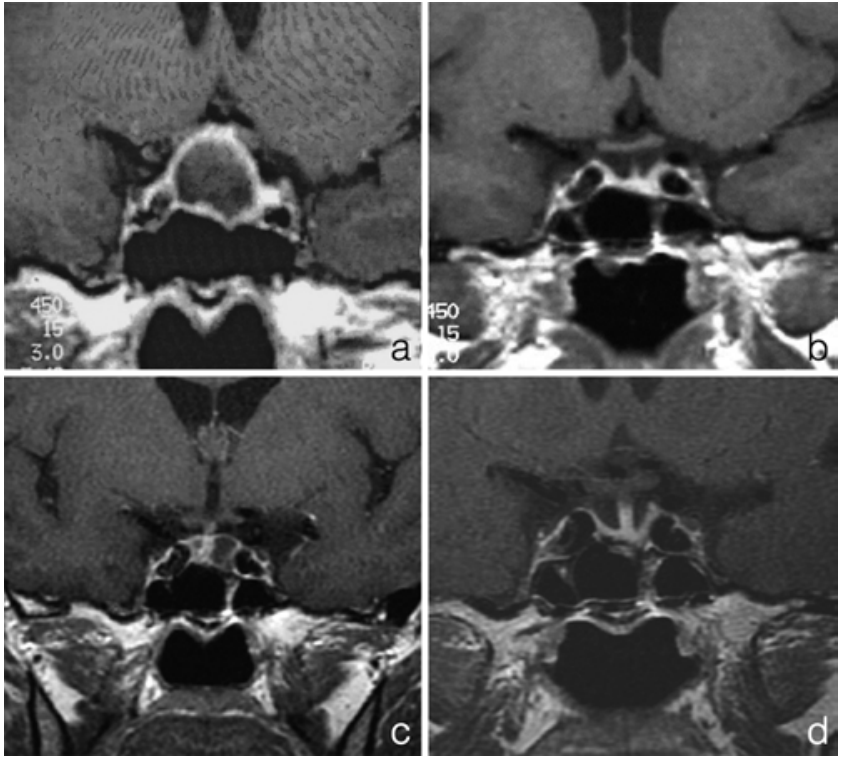

FIG. 2. Case 1. Coronal Gd-enhanced MR images. a: The cystic pituitary adenoma that caused the patient's visual disturbances is shown. $\mathbf{b}$ : Radical removal with sparing of the residual gland is evident. c: An endosellar recurrence with cavernous sinus infiltration occurred on the left side after 3 years. d: Complete tumor removal is apparent.

sol $221 \mathrm{ng} / \mathrm{ml}$; urinary free cortisol $77 \mu \mathrm{g} / 24$ hours). The recurrent tumor was partially removed through a second endoscopic transsphenoidal surgery, and a small remnant was left in the cavernous sinus. Histopathological analysis did not show substantial change compared with the specimen obtained at the first surgery. In the ensuing years, MRI showed a stable remnant. However, the patient experienced a subtle and slow progressive increase in her body weight and blood pressure (the latter requiring frequent adjustment of her medical therapy). During these years, her serum and urinary cortisol levels, measured at yearly endocrinological follow-up visits, were within normal limits, although they did trend upward (cortisol $220 \mathrm{ng} /$ $\mathrm{ml}$; urinary free cortisol $88 \mu \mathrm{g} / 24$ hours), while her serum ACTH levels remained slightly elevated (up to $88 \mathrm{pg} / \mathrm{ml}$ ).

By 2007, her weight had continued to increase, and she also complained of fatigue and weakness. Her serum ACTH level was $61 \mathrm{pg} / \mathrm{ml}$; however, her serum cortisol $(253 \mathrm{ng} / \mathrm{ml})$ and urinary free cortisol $(240 \mu \mathrm{g} / 24$ hours $)$ levels were elevated. An LDDST resulted in a lack of suppression of serum cortisol $(158 \mathrm{ng} / \mathrm{ml})$. Although MRI did not show any change in the appearance of the residual tumor, she underwent resection through a transsphenoidal approach because of the clinical and endocrinological changes. Histopathological analysis revealed increased positive staining for ACTH compared with that from the previous resection (Table 2). A radical tumor resection was accomplished, but the hypercortisolism was not corrected (Fig. 2d). Indeed, her serum cortisol level remained at $265 \mathrm{ng} / \mathrm{ml}$, her urinary free cortisol level remained at $102 \mu \mathrm{g} / 24$ hours, and her ACTH level was $31 \mathrm{pg} / \mathrm{dl}$. An LDDST was performed once again, but no suppression of serum cortisol was achieved. Thus, cabergoline and ketoconazole were started, and Gamma Knife radiosurgery
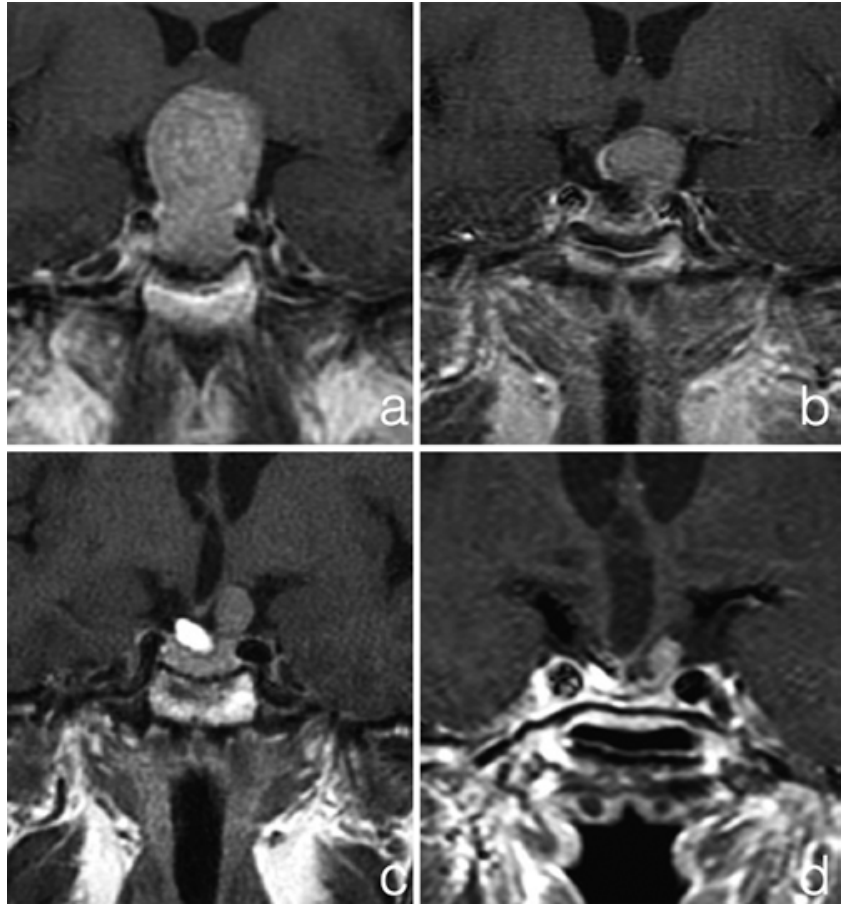

FIG. 3. Case 2. Coronal Gd-enhanced MR images. a: A pituitary adenoma with suprasellar extension is present. $\mathbf{b}$ : Resection was incomplete, and a left suprasellar mass is evident. c: After the second endoscopic endonasal surgery, the tumor remnant was partially removed. The repair with abdominal fat and fascia lata is evident. $\mathbf{d}$ : After the extended transplanum/transtuberculum approach, the adenoma was not removed completely.

was performed 1 year later. At the first yearly follow-up visit after the radiosurgery, the patient's urinary free cortisol (116 $\mu \mathrm{g} / 24$ hours) and serum cortisol (341 ng/ml) levels were still elevated, and her serum ACTH level was at the upper limit of normal $(60 \mathrm{pg} / \mathrm{ml})$. Moreover, her arterial pressure was refractory to maximal medical therapy. Hence, a second Gamma Knife treatment was performed in April 2010. Because this additional procedure did not control her cortisol level, she eventually underwent bilateral adrenalectomy and started replacement corticosteroid therapy, which resulted in significant weight loss (17 kg) and better medical control of her arterial pressure. At the last follow-up visit (September 2014), her weight remained under control and brain MRI did not show any recurrence.

\section{Case 2}

A 51-year-old man was referred to our center in April 2003 for visual disturbances and a body habitus suggestive of Cushing disease. He had a history of diabetes mellitus and arterial hypertension that required pharmacological treatments. An ophthalmological examination revealed a complete bitemporal hemianopia, and MRI showed a pituitary adenoma with suprasellar extension (Fig. 3a). Biochemical assay results confirmed the clinical suspicion of endogenous hypercortisolism by revealing ACTH-dependent Cushing syndrome (serum ACTH $130 \mathrm{pg} / \mathrm{ml}$ [reference range 5-60 pg/ml]; serum cortisol $310 \mathrm{ng} / \mathrm{ml}$ [reference range $70-210 \mathrm{ng} / \mathrm{ml}$; urinary free cortisol $146 \mu \mathrm{g} / 24$ hours [reference range $20-90 \mu \mathrm{g} / 24$ hours]). His baseline 
serum LH and FSH levels were decreased. He underwent endoscopic transsphenoidal surgery, and partial tumor removal was achieved. Histopathological evaluation of the tumor revealed a densely granulated corticotroph adenoma with positive staining for ACTH in $90 \%$ of the cells (Table 2). His postoperative course was uneventful, although his serum cortisol level remained elevated at discharge.

At the 3-month follow-up visit, the patient's visual deficits had improved, and MRI confirmed a residual suprasellar tumor (Fig. 3b). Serum hypercorticism was still present (ACTH $72.5 \mathrm{pg} / \mathrm{ml}$; plasma cortisol $180 \mathrm{ng} / \mathrm{ml}$; and urinary free cortisol $83 \mu \mathrm{g} / 24$ hours), and an LDDST confirmed the persistence of Cushing disease by showing no serum cortisol suppression. Thus, 6 months later, a second endoscopic transsphenoidal surgery was performed with again only subtotal resection. Histopathological analysis did not reveal substantial change. Although postoperative MRI showed the presence of the remnant in the suprasellar space (Fig. 3c), after 1 month the patient unexpectedly presented with a weight loss of $14 \mathrm{~kg}$ and a normalization of hypercortisolism (ACTH $48.6 \mathrm{pg} / \mathrm{dl}$; urinary free cortisol $35 \mu \mathrm{g} / 24$ hours; and plasma cortisol $71.7 \mathrm{ng} / \mathrm{ml}$ ). In the following months, the spontaneous remission of Cushing disease progressed to hypocorticism (plasma cortisol $10 \mathrm{ng}$ / $\mathrm{ml}$; urinary free cortisol $9.7 \mu \mathrm{g} / 24$ hours), and the patient started replacement corticosteroid therapy. In 2006, routine MRI showed an increase in the tumor remnant, which caused further worsening of his visual function. Therefore, surgery was again performed via an endoscopic endonasal extended transplanum/transtuberculum approach. The resection was extensive but again incomplete, as demonstrated by MRI 3 months later (Fig. 3d). The histopathological analysis revealed a tumor with features similar to those of the previous tumors (Table 2). Unfortunately, postoperative ischemia of the pons occurred, resulting in permanent hemiparesis. Visual deficits normalized 3 months after surgery, and mild hypoadrenalism was confirmed after the Synacthen test. At follow-up in September 2014, the patient was still receiving hydrocortisone replacement therapy for his hypoadrenalism. MRI showed that the tumor remnant was unchanged, and his visual field was normal.

\section{Case 3}

An 18-year-old woman was admitted in November 2006 after undergoing 2 microscopic transsphenoidal surgeries elsewhere in 2004 and 2005 for a partially cystic pituitary adenoma with suprasellar extension and invasion of both the cavernous sinuses. Histopathological examination had revealed an adenoma with immunoreactivity to ACTH. Because there were no somatic or biohumoral findings of Cushing disease, a silent ACTH adenoma was diagnosed. At admission to our center, neuroimaging showed an increase in the size of the residual tumor and a relevant cystic component (Fig. 4a). She had primary amenorrhea, her weight was $47 \mathrm{~kg}$, and her height was $158 \mathrm{~cm}$. The results of an evaluation of her hypothalamic-pituitaryadrenal axis were normal (serum cortisol $220 \mathrm{ng} / \mathrm{ml}$ [reference range $56-230 \mathrm{ng} / \mathrm{ml}$ ]; ACTH $40 \mathrm{pg} / \mathrm{dl}$ [reference range $0-46 \mathrm{pg} / \mathrm{dl}]$ ). A decreased serum level of insulinlike growth factor 1 for age and sex $(76 \mathrm{ng} / \mathrm{ml})$ led to the suspicion of growth hormone deficiency, which was sub-
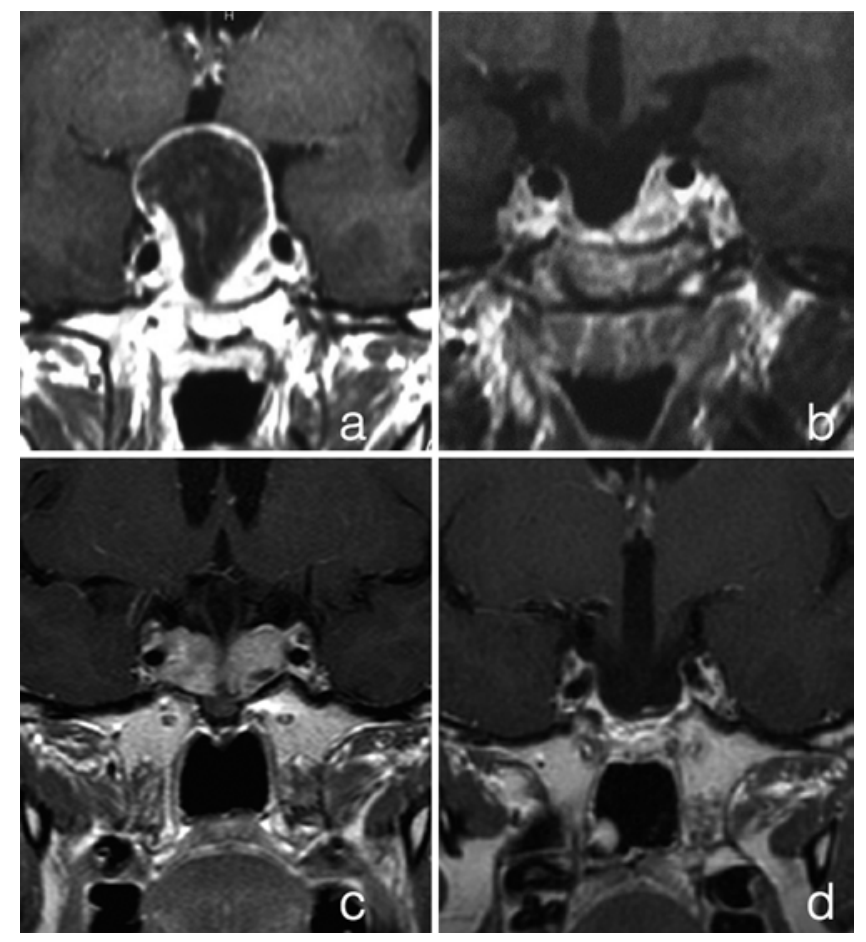

FIG. 4. Case 3. Coronal Gd-enhanced MR images. a: An endosellar/ suprasellar and parasellar pituitary adenoma with a relevant cystic component is shown. b: Surgical resection was incomplete, and the left parasellar remnant is evident. c: After 6 years, regrowth of the remnant is shown. $\mathrm{d}$ : Radical removal of the tumor is apparent.

sequently demonstrated by a stimulation test with growthhormone-releasing hormone plus arginine. Surgery was performed through an endoscopic endonasal approach, and subtotal tumor removal was achieved. Her postoperative course was unremarkable. In the histopathological examination, immunostaining the tumor revealed a Type I corticotroph adenoma, and $20 \%$ of the cells were positive for ACTH (Table 2). Brain MRI performed 3 months after surgery confirmed the presence of a small remnant in the left cavernous sinus (Fig. 4b). The patient's visual deficits improved, and her endocrinological function was unchanged. Substitutive treatment with recombinant human growth hormone was suggested, but it was stopped after few months because of poor compliance. Routine annual ophthalmological, endocrinological, and neuroradiological examinations indicated that her condition was stable until September 2012, when she presented with a weight gain of $6 \mathrm{~kg}$. Follow-up MRI showed a recurrence of the tumor with bilateral parasellar extension, and biohumoral assays revealed hypercorticism (serum cortisol $412 \mathrm{ng} / \mathrm{ml}$; ACTH $21.51 \mathrm{pg} / \mathrm{dl}$; urinary free cortisol $210 \mu \mathrm{g} / 24$ hours) (Fig. 4c). An LDDST confirmed the lack of suppression of serum cortisol, consistent with the diagnosis of Cushing disease. A second surgery was performed through an endoscopic endonasal approach, in which radical resection of the tumor was achieved. Histopathological analysis revealed an increase in the rate of cells positive for ACTH immunostaining over that in the tumor from the first surgery (Table 2). A decrease in her cortisol level $(25 \mathrm{ng} / \mathrm{ml})$ was observed 2 days after surgery, and hydrocortisone re- 
placement therapy was started. Postoperative MRI showed a radical resection of the tumor (Fig. 4d). At the endocrinological examination, the patient presented with anterior panhypopituitarism, and complete hormone replacement treatment was suggested. At last follow-up in September 2014 , the patient had recovered to her weight of $48 \mathrm{~kg}$, no recurrence of the tumor was observed, and she was still on hormone (including hydrocortisone) replacement therapy.

\section{Case 4}

A 37-year-old woman presented in September 2006 after microscopic transsphenoidal surgery performed elsewhere in 2005 for an invasive pituitary adenoma. The resection was partial, and the patient had been on medical therapy, with cabergoline and octreotide, for 12 months. In a histopathological examination, the tumor was strongly positive for ACTH immunostaining. Preoperative biochemical analysis had detected a high ACTH level (386 pg/ $\mathrm{ml}$ [reference range $9-52 \mathrm{pg} / \mathrm{ml}$ ]), whereas her serum cortisol and urinary free cortisol levels were normal. Because no sign of Cushing syndrome was present at that time, a silent corticotroph adenoma was diagnosed. However, when she was admitted to our center, she was clearly presenting typical somatic features of Cushing disease, along with dysmenorrhea and arterial hypertension. An endocrinological assessment revealed a remarkable increase in her serum ACTH (up to $1500 \mathrm{pg} / \mathrm{ml}$ ), urinary free cortisol (630 mg/24 hours [reference range 36-137 mg/24 hours]), and serum cortisol (107.4 ng/ml [reference range 62-194 $\mathrm{ng} / \mathrm{ml}]$ ) levels with no suppression after an LDDST. Brain MRI showed a sellar/suprasellar adenoma with bilateral cavernous sinus invasion (Fig. 5a). Surgery was performed through a transsphenoidal endoscopic approach, and the tumor was partially removed. The postoperative course was unremarkable, but the hypercorticism did not improve. In the histopathological evaluation, an intense positivity for ACTH immunostaining was present (Table 2).

Follow-up MRI 3 months later showed a residual tumor in the suprasellar region (with a subfrontal expansion) and in the right cavernous sinus. However, biohumoral assays after 6 months showed normalization of the patient's serum cortisol $(6.4 \mathrm{ng} / \mathrm{ml})$ and urinary free cortisol (46 $\mathrm{mg} / 24$ hours) levels and a marked reduction of her ACTH level $(150 \mathrm{pg} / \mathrm{ml})$. Thus, corticosteroid replacement treatment was started. For the tumor remnant, a second surgery was performed 9 months later; in this, an endoscopic endonasal approach was extended to the planum/tuberculum, but the tumor removal again was partial (Fig. 5b). Histopathological analysis showed a reduction in the rate of cells positive for ACTH immunostaining compared to that in the tumor from the previous surgery. As for endocrinological control, biohumoral assays 3 months after surgery indicated that the patient's condition was stable, and she was still receiving corticosteroid replacement therapy.

Annual brain MRI demonstrated that the tumor remained unchanged until January 2009, when the patient underwent a craniotomy for further growth of a suprasellar asymmetrical remnant on the right side. Histopathological analysis did not reveal any relevant changes in the tumor. The patient continued her clinical and neuroradiological follow-up evaluations without any modifications until Au-
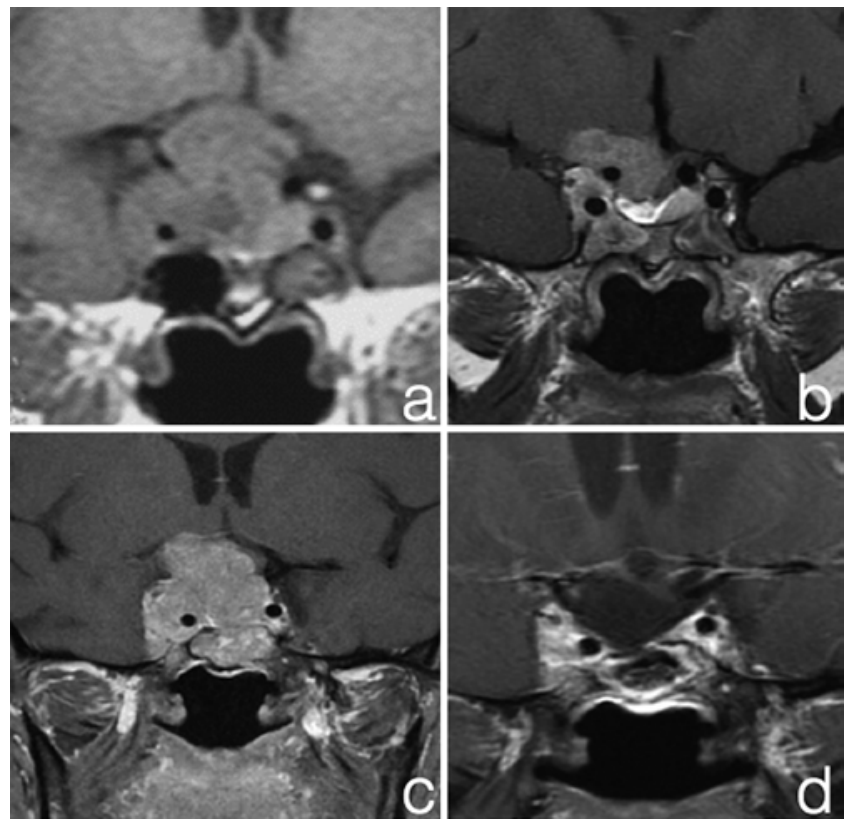

FIG. 5. Case 4. Coronal Gd-enhanced MR images. a: A bilateral endosellar/suprasellar/parasellar tumor in the cavernous sinuses is visible. b: After 2 endoscopic endonasal procedures (1 standard and 1 extended transplanum/transtuberculum), partial tumor removal was achieved. c: Growth of the tumor despite another transcranial surgery is evident. $\mathbf{d}$ : After a subsequent endoscopic endonasal surgery, the tumor was not removed completely; a remnant in the right cavernous sinus is visible.

gust 2012, when she began to complain of visual deficits and an incomplete bitemporal hemianopsia was detected. MRI showed further growth of the adenoma remnant (Fig. 5c). A recurrence of Cushing disease was suspected at the physical examination. Laboratory tests revealed an increase in her serum ACTH (608 ng/L), serum cortisol (445 ng/ml), and urinary free cortisol (540 mg/24 hours) levels and a lack of suppression after an LDDST. Thus, another surgery was performed through an extended endoscopic endonasal approach, and subtotal removal of the tumor was achieved. Histopathological analysis of the tumor revealed ACTH immunostaining positivity of $75 \%$ (Table 2). Unfortunately, 15 days after surgery, the patient presented with a dramatic and abrupt worsening of vision in her right eye, resulting in complete blindness. Three months later MRI showed a small remnant in the right cavernous sinus (Fig. 5d). Six months after surgery, the ACTH and plasma cortisol values were decreased (107 pg/ml and $164 \mathrm{ng} / \mathrm{ml}$, respectively), suggesting another shift of the tumor to a nonfunctioning form. At the last follow-up visit in May 2014, the patient's visual deficit was unchanged and the tumor remnant was stable. Her ACTH levels were still elevated (143 pg/ml), but she required hydrocortisone replacement therapy for secondary adrenal insufficiency. These features support the hypothesis of absent or reduced biological activity of $\mathrm{ACTH}$ secreted by the tumor at this stage of the disease.

\section{Case 5}

A 49-year-old man was referred to us in September 2009 for an intrasellar/parasellar adenoma invading the left cav- 
ernous sinus that had been diagnosed incidentally 2 years earlier after persistent dizziness (Fig. 6 left). At that time (2007), biohumoral assay results had been consistent with a nonfunctioning adenoma. His serum cortisol level was $133 \mathrm{ng} / \mathrm{ml}$ (reference range 70-250 ng/ml), his ACTH level was $48.8 \mathrm{pg} / \mathrm{ml}$ (reference range 5-52), and his urinary free cortisol level was $299.6 \mu \mathrm{g} / 24$ hours (reference range 58-400 $\mu \mathrm{g} / 24$ hours). Conservative treatment was chosen, and the patient was evaluated every 6 months. There were neither clinical nor biochemical changes until 2009, when the patient complained of weight gain, fatigue, and diffuse muscle pain. Laboratory tests revealed an increase of his serum cortisol (306 ng/ml), plasma ACTH (127.9 pg/ $\mathrm{ml}$ ), and urinary free cortisol (1307.5 $\mu \mathrm{g} / 24$ hours) levels. An LDDST confirmed the diagnosis of Cushing disease. There were no changes in tumor appearance on brain MRI. A left ethmoidopterygosphenoidal approach was used for radical removal of the tumor. In the first 48 hours after surgery, the serum cortisol level had fallen to $35 \mathrm{ng} / \mathrm{ml}$ and replacement therapy with hydrocortisone was started. In the histopathological analysis, the tumor presented an intense positivity for ACTH immunostaining (Table 2). Follow-up MRI 3 months later confirmed radical tumor removal (Fig. 6 right). An endocrinological evaluation revealed hypocorticism, which required hydrocortisone replacement therapy for 12 months. At last follow-up in September 2014, the patient was in good health and no longer required hydrocortisone replacement treatment. No recurrence of the tumor was observed on MRI, and his serum cortisol and ACTH levels were normal.

\section{Discussion}

At the end of the 1970s, Kovacs et al.9,12 described silent corticotroph cell adenoma as a new clinicopathological entity that presents with positive ACTH immunostaining without any clinical or biochemical features of Cushing disease. Since then, the great majority of investigations about these tumors have been focused on their supposedly greater invasiveness and aggressiveness than other nonfunctioning pituitary adenomas..$^{5,10,14,19}$ Silent corticotroph cell adenomas are mostly macroadenomas and are commonly associated with cystic components; the diagnosis is often delayed when visual disturbances occur. ${ }^{5,10,14,19} \mathrm{Al}$ - though the possibility for these tumors to transform into Cushing disease was reported a few years after the first description, ${ }^{6,17}$ this phenomenon and its clinical relevance have been poorly considered in the literature. Indeed, just a few similar cases have been reported, mostly in isolated case reports or series not focused on this topic, and no overall view of this phenomenon and its clinical implica-

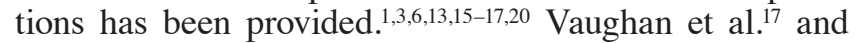
Cooper et al. ${ }^{6}$ were among the first to report the development of Cushing disease from a previously silent ACTH adenoma. Subsequently, a few other authors have reported this same phenomenon and have shown the potential of silent ACTH adenomas to shift to a functioning form during the follow-up period, even many years after the initial diagnosis. ${ }^{1,13,15,16,20}$ It is interesting to note that Brown et al. ${ }^{3}$ demonstrated the possibility of silent ACTH adenomas evolving into corticotropin-secreting carcinomas long after the initial diagnosis (16 years).

In our series, we found 5 cases of patients who presented with a transformation of the clinical and biochemical expressions of these tumors in the follow-up period. Our investigation was retrospective and, as such, suffers from some limitations, because it is possible that not every case had a complete biochemical diagnostic workup. Nevertheless the workup of every single case was in line with the current guidelines of the Endocrine Society. We observed that the tumor shifted from a silent to a functioning form in 3 cases and from Cushing disease to a silent adenoma in 1 case, and both transformations occurred in 1 case. We found that the transformation from a silent ACTH adenoma to a functioning tumor occurred in $9 \%$ of our cases of silent ACTH adenomas. Therefore, the shift of silent ACTH adenoma to a functioning form is rare but not anecdotal. Also, Baldeweg et al. ${ }^{2}$ reported that in $26 \%$ of silent corticotroph cell adenomas, a clinical manifestation of Cushing disease occurred at late follow-up. These data are consistent with ours, which show how the clinical and biochemical expressions of hypercorticism can occur after a long period of time (up to 7 years in our experience). Conversely, in our experience the spontaneous resolution of Cushing disease for the shift of a functioning adenoma to a silent corticotroph cell tumor is very rare. We observed this phenomenon in only $1.5 \%$ of our series of ACTH ad-
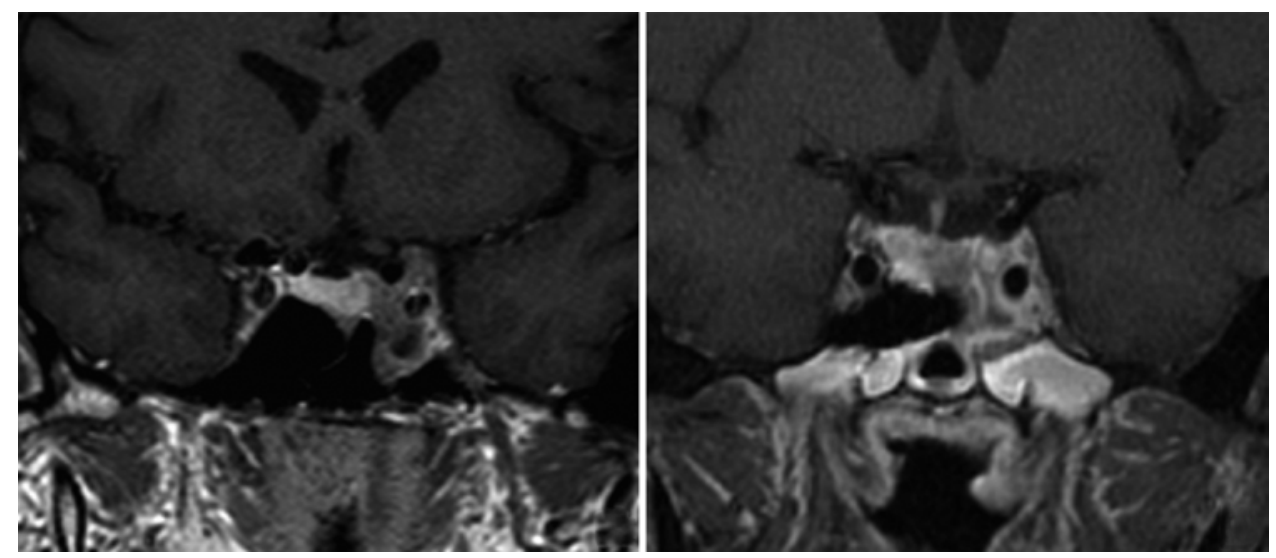

FIG. 6. Case 5. Coronal Gd-enhanced MR images. Left: An endosellar adenoma invading the left cavernous sinus is shown. Right: Radical removal with sparing of the pituitary gland is apparent. 
enoma with Cushing disease. This is consistent with what has been reported in the literature, in which similar cases have been reported very rarely, as described by Dickstein et al. ${ }^{7}$ and Ishibashi et al. ${ }^{11}$ It could be argued that some of our cases may be explained by the phenomenon of cyclic cortisol secretion variations (so-called cyclic Cushing syndrome). Cyclic Cushing syndrome has been reported especially in ACTH-independent Cushing syndrome and rarely in ACTH-dependent Cushing syndrome, both in cases of microadenomas and ectopic ACTH secretion. ${ }^{8,18}$ In the cyclic form of ACTH-dependent Cushing syndrome, the hypersecretion of ACTH shows a cyclic or intermittent pattern. As a result, serum ACTH levels together with cortisol serum levels normalize in the clinical remission phase of the disease. However, in our cases, serum ACTH levels remained elevated even when patients did not show classical clinical features of Cushing syndrome and the serum cortisol level was normal. Besides cyclic Cushing syndrome, the possibility of mild or subclinical Cushing syndrome also should be considered in the debate on the transformation from a silent to a secreting corticotroph cell adenoma. However, this form is observed more frequently in ACTHindependent Cushing syndrome than in ACTH-dependent Cushing syndrome or in Cushing disease, although some exceptions do exist. ${ }^{4}$ The mechanism(s) underlying the transformation of a corticotropic adenoma from a secreting to a silent form and vice versa are still unknown. It has been suggested that the ACTH secreted by corticotropic adenomas may have decreased biological activity, thus requiring a longer period of time to express the features of Cushing disease. ${ }^{2}$ This hypothesis can explain those cases that show a gradual and subtle shift to hypercortisolism long after the initial diagnosis or when the shift occurs after very high levels of serum ACTH are reached. It is interesting to note that this hypothesis is consistent with what we observed in our Case 4. Indeed, this patient did not show clinical or biochemical findings of Cushing disease despite high plasma ACTH levels, but these features developed when her plasma ACTH levels increased to very high values (e.g., $1500 \mathrm{pg} / \mathrm{ml}$ ). A second hypothesis suggests that one or more modifications of the structure of the ACTH molecules secreted by the tumor could be the basis of the phenomeon..$^{15}$ These changes may have the ability to increase or reduce the biological activity of $\mathrm{ACTH}$, thus inducing Cushing disease or its spontaneous remission. ${ }^{15}$ This idea might also explain those cases with a rapid onset or abrupt spontaneous remission of Cushing disease. However, further molecular studies are needed to investigate the genesis of this phenomenon. The wide spectrum of transformations that we have presented herein make us inclined to believe that a unique mechanism is unlikely to explain the phenomenon in all its variants. The transformation of a silent corticotroph cell adenoma into Cushing disease is a challenge not only for researchers but also for clinicians and neurosurgeons. In fact, this phenomenon is often unexpected. Thus, strict and careful follow-up is mandatory. Moreover, the follow-up should be focused on not only neuroimaging to identify recurrences or regrowth of remnants but also the clinical and biochemical features to identify precociously the development of Cushing disease. Furthermore, these cases are usually more surgi- cally demanding and require multiple and more extended interventions or complementary treatments. Indeed, unlike most ACTH-secreting adenomas, these tumors are usually macroadenomas and commonly of a relevant size and sometimes locally invasive; thus, the radical removal required to control the hypercorticism might be more difficult to achieve and may require expanded endoscopic approaches to the suprasellar or cavernous sinus region or even combination with transcranial interventions because of the asymmetrical growth of the tumor, as we observed in our experience. Moreover, the spontaneous remission of Cushing disease caused by transformation of the tumor to a silent adenoma can lead to misinterpretation of the clinical results. In these cases, the postoperative normalization of serum cortisol is a result of the biological behavior of the tumor and not the radical removal by the surgeon. A very strict follow-up is required to avoid missing the growth of the remnants and because hypersecretion can develop once more even after a long time, as observed in our Case 4. In conclusion, silent corticotroph cell adenomas can have bizarre and unpredictable postoperative behavior, potentially changing their secretion multiple times or evolving to carcinoma. ${ }^{3}$ This situation can lead one to erroneously consider a case as under control, when it can instead evolve into Cushing disease or can be one in which secretion is switched from a functioning to a silent form.

\section{Conclusions}

Silent corticotroph cell adenoma is a continuing challenge for neurosurgeons and endocrinologists. In particular, the ability of these adenomas to transform their patterns of secretion is very insidious. This shift is often unexpected, and the clinical and laboratory findings may be underestimated, thus leading to delayed or missed diagnosis. For the surgeon, these cases are usually more complex, because unlike most ACTH adenomas, they are macroadenomas and sometimes invasive, which can require multiple and extended surgical approaches. Finally, they can present bizarre and unpredictable postoperative behavior, potentially changing their secretion multiple times, which can lead one to consider a case as under control when it may instead be transiently silent and reactivate in the follow-up period. Thus, very strict clinical, laboratory, and neuroimaging follow-up examinations are mandatory for all ACTH-silent adenomas to detect precociously their possible transformation into Cushing disease. Even if these cases are very rare, they are not anecdotal in large series, and their underestimation could be a result of the complexity of their diagnosis and the need for a long follow-up period.

\section{References}

1. Ambrosi B, Colombo P, Bochicchio D, Bassetti M, Masini B, Faglia G: The silent corticotropinoma: is clinical diagnosis possible? J Endocrinol Invest 15:443-452, 1992

2. Baldeweg SE, Pollock JR, Powell M, Ahlquist J: A spectrum of behaviour in silent corticotroph pituitary adenomas. Br J Neurosurg 19:38-42, 2005

3. Brown RL, Wollman R, Weiss RE: Transformation of a pituitary macroadenoma into to a corticotropin-secreting carcinoma over 16 years. Endocr Pract 13:463-471, 2007

4. Chiodera P, Volpi R, Bianconcini M, Bortesi ML, Manfredi 
G, Coiro V: Desmopressin test in occult eutopic corticotroph microadenoma. Arch Intern Med 162:840-841, 2002

5. Cho HY, Cho SW, Kim SW, Shin CS, Park KS, Kim SY: Silent corticotroph adenomas have unique recurrence characteristics compared with other nonfunctioning pituitary adenomas. Clin Endocrinol (Oxf) 72:648-653, 2010

6. Cooper ME, Murray RM, Kalnins R, Woodward J, Jerums G: The development of Cushing's syndrome from a previously silent pituitary tumour. Aust N Z J Med 17:249-251, 1987

7. Dickstein G, Arad E, Shechner C: Late complications in remission from Cushing disease. Recurrence of tumor with reinfarction or transformation into a silent adenoma. Arch Intern Med 157:2377-2380, 1997

8. Farage M, Costa MA, Godoy-Matos AF: A rare case of Cushing syndrome by cyclic ectopic-ACTH. Arq Bras Endocrinol Metabol 56:324-330, 2012

9. Horvath E, Kovacs K, Killinger DW, Smyth HS, Platts ME, Singer W: Silent corticotropic adenomas of the human pituitary gland: a histologic, immunocytologic, and ultrastructural study. Am J Pathol 98:617-638, 1980

10. Ioachimescu AG, Eiland L, Chhabra VS, Mastrogianakis GM, Schniederjan MJ, Brat D, et al: Silent corticotroph adenomas: Emory University cohort and comparison with ACTH-negative nonfunctioning pituitary adenomas. Neurosurgery 71:296-304, 2012

11. Ishibashi M, Shimada K, Abe K Furue H, Yamaji T: Spontaneous remission in Cushing's disease. Arch Intern Med 153:251-255, 1993

12. Kovacs K, Horvath E, Bayley TA, Hassaram ST, Ezrin C: Silent corticotroph cell adenoma with lysosomal accumulation and crinophagy. A distinct clinicopathologic entity. Am J Med 64:492-499, 1978

13. Melcescu E, Gannon AW, Parent AD, Fratkin JF, Nicholas WC, Koch CA, et al: Silent or subclinical corticotroph pituitary macroadenoma transforming into Cushing disease: 11-year follow-up. Neurosurgery 72:E144-E146, 2013

14. Raverot G, Wierinckx A, Jouanneau E, Auger C, BorsonChazot F, Lachuer J, et al: Clinical, hormonal and molecular characterization of pituitary ACTH adenomas without (silent corticotroph adenomas) and with Cushing's disease. Eur J Endocrinol 163:35-43, 2010

15. Salgado LR, Machado MC, Cukiert A, Liberman B, Kanamura CT, Alves VA: Cushing's disease arising from a clinically nonfunctioning pituitary adenoma. Endocr Pathol 17:191-199, 2006

16. Tan EU, Ho MS, Rajasoorya CR: Metamorphosis of a non-functioning pituitary adenoma to Cushing's disease. Pituitary 3:117-122, 2000

17. Vaughan NJ, Laroche CM, Goodman I, Davies MJ, Jenkins JS: Pituitary Cushing's disease arising from a previously non-functional corticotrophic chromophobe adenoma. Clin Endocrinol (Oxf) 22:147-153, 1985

18. Velez DA, Mayberg MR, Ludlam WH: Cyclic Cushing syndrome: definitions and treatment implications. Neurosurg Focus 23(3):E4, 2007

19. Wass JA, Reddy R, Karavitaki N: The postoperative monitoring of nonfunctioning pituitary adenomas. Nat Rev Endocrinol 7:431-434, 2011

20. Yokoyama S, Kawahara Y, Sano T, Nakayama M, Kitajima S, Kuratsu J: A case of non-functioning pituitary adenoma with Cushing's syndrome upon recurrence. Neuropathology 21:288-293, 2001

\section{Author Contributions}

Conception and design: Faustini-Fustini, Bacci, Pasquini, Frank. Acquisition of data: Zoli, Marucci, De Carlo, Bacci. Analysis and interpretation of data: Zoli, Faustini-Fustini, Marucci. Drafting the article: Zoli, Faustini-Fustini, Marucci, De Carlo. Critically revising the article: Zoli, Faustini-Fustini, Mazzatenta, Pasquini, Lanzino, Frank. Reviewed submitted version of manuscript: Faustini-Fustini, Mazzatenta, Pasquini, Lanzino. Study supervision: Mazzatenta, Frank.

\section{Correspondence}

Matteo Zoli, Center of Pituitary Tumors and Endoscopic Skull Base Surgery, IRCCS Scienze Neurologiche, Via Altura, Bologna 40139, Italy. email: matteozeta@libero.it. 